\title{
Drawbacks of a medium sized, grid coupled Photo Voltaic Array
}

\author{
C. Keyer ${ }^{1,2}$, I. Setiawan ${ }^{2}$, F. Leferink ${ }^{2,3}$ \\ ${ }^{1}$ University of applied science Amsterdam \\ Weesperzijde 1901097 DZ Amsterdam the Netherlands \\ e-mail: c.h.a.keyer@hva.nl \\ ${ }^{2}$ Twente University \\ Drienerlolaan 5, 7522 NB Enschede the Netherlands \\ c.h.keyer@utwente.nl \\ ${ }^{3}$ Thales Nederland bv \\ Zuidelijke Havenweg 40, 7554 RR Hengelo the Netherlands
}

\begin{abstract}
A medium sized photo voltaic (PV) array with good inverters produces high quality, real (true) power.. The maximum allowable reactive power is a percentage of the real power consumed from the grid. Before the PV array was installed the reactive power was less than $50 \%$ of the real power, which is allowed by the by-laws. Because of the amount of PV generated real power the actual consumed real power reduced. The ratio of reactive power to the consumed power changed therefore drastically. According the by-laws and the utility the eactive power drawn from the power grid is too high and the owner of the PV installation now has to pay a fine.
\end{abstract}

\section{Key words}

Photo voltaic array, apparent power, real power, reactive power fine.

\section{Introduction}

In the Netherlands more and more companies are using Photo Voltaic (PV) systems to reduce their energy consumption from the public grid. This is from an ecological point of view a correct and sensible thing to do. The inverters are capable to deliver, in terms of electromagnetic interference (EMI), clean power: very low harmonic distortion and exactly in-phase, and thus real power. The power consumption from the public grid was before the installation of the PV installation a mix of real and reactive power, but the amount of reactive power remained below the threshold for paying a fine. However, after installing the PV inverters, the sum of consumed and delivered real power was reduced while the amount of reactive power remained more or less constant. This results in a fine from the power utility and thus higher cost for the PV owner, reducing the return-on-investment of the $\mathrm{PV}$ installation. This paper describes the results of an actual case study performed in Balkbrug in the Netherlands.

\section{Installation description}

A large potato distributor has several large storage halls. The company is connected to the public power grid by a dedicated transformer $10 \mathrm{kV} / 230 \mathrm{~V}$ and the PV system injects power at several places, see Figure 1 and Figure 2, in the local power grid. The total area of solar panels on the roof is approximately $2800 \mathrm{~m}^{2}$ and the generated power peaks at $414 \mathrm{~kW}$ (dc power).

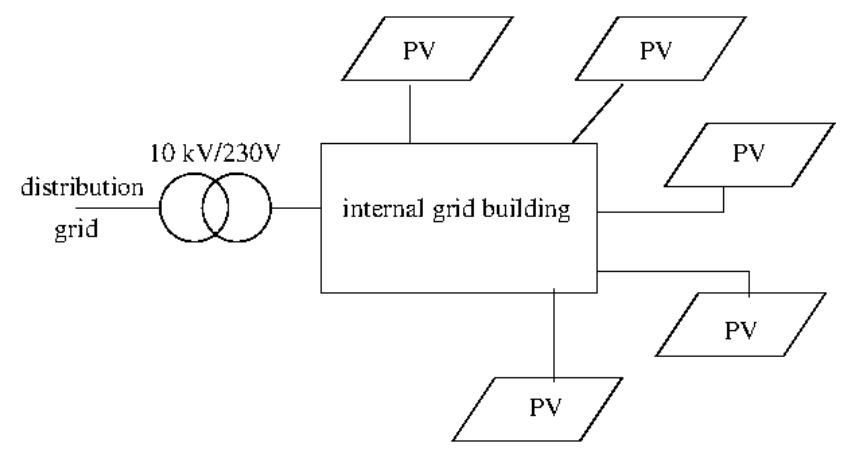

Figure 1: Overview power grid

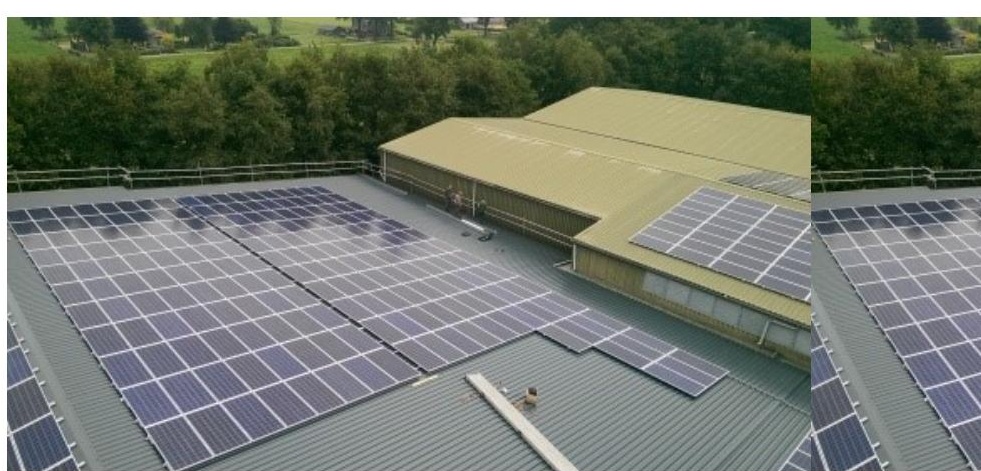

Figure 2: A small part of the PV panels on the roof picture courtesy Agrisun bv the Netherlands.

The arrays of PV cells are connected to the local power grid by several inverters from ABB type TRIO 27.6. These inverters are coupled in clusters of 2 or 3 inverters 
per infeed point. The distributed clusters over the building do not communicate between the clusters.

\section{Power measurement law and bylaws}

In the Netherlands, measurement of the power and reactive power is governed by law and bylaws. The law which rules power distribution, in Dutch Elektriciteitswet, states in article 95la paragraph 1 [1] that the measurement for invoices are ruled in a bylaw. The advantage of rules in bylaws is that the bylaws are not controlled by the democratic process, hence it is quite easy to change the bylaw and adjust the rules for new developments. There are two important bylaws governing the Dutch power market. The bylaw Netcode which is used for the distribution net. The bylaw Meetcode is used for regulating the measurement equipment for the billing towards the consumers and companies who have a grid connection.

\section{Possibility of interference}

Energy generated through the PV is fed into the power grid using Active Infeed Converters (AIC). The lack of proper Electromagnetic Interference (EMI) standards, especially in the range $2-150 \mathrm{kHz}$, created possibilities to generate high interference levels, causing EMI [1]. Two neighboring farmers using the same PV system observed that on sunny days one PV generated only $40 \%$ of the energy generated by the other. It was found that the power drive systems for the fans in the barn generated high conducted interference on the power lines and the static energy meter failed to register the actual value. The problem could be solved by replacing the power drive system [3]. A similar case was observed during experimentation with PV installations in Germany. In other cases high interference levels generated by AICs were also observed, which caused faulty readings of the static energy meters [4]. This observation, possibly combined with a higher number of complaints and failures, resulted in faster publication of the TR50579 [5] technical report and IEC 61000-4-19 standard [6].

In [7] an overview of techniques used by integrated circuit manufacturers such as Texas Instruments, Analog Devices, ST and Maxim, it is shown that there are various options for signal processing. In case the reactive power and energy are measured, the different metrics corresponding to different mathematical models can provide conflicting results for non-sinusoidal conditions [8], e.g. $90^{\circ}$ shifting of the voltage by means of an integrator, or by means of a time shift of a quarter of a period, or digital implementation of the definition of the "non-active power". Measurements showed differences of up to $52 \%$ [8], and $-61 \%$ to $+47 \%$ [9]. It is also stated in the IEEE 1459 standard [11]: 'VARmeters that use $90^{\circ}$ phase shift in time of fundamental may measure correctly the reactive power under sinusoidal conditions. When the voltage and current waveforms are highly distorted, such meters yield a reading that has questionable significance'.

\section{Measurement setup and results}

The measurement setup as shown in Figure 3 was used to find anomalies in current and voltage waveforms. The 8 channel oscilloscope is a $20 \mathrm{MHz}$ picoscope 4824 . The current probes are switchable between 200 and 2000 ampere. Bandwidth of the current probes is limited to 20 $\mathrm{kHz}$. The voltage measurements are performed with a resistive voltage divider $(1: 1000)$.

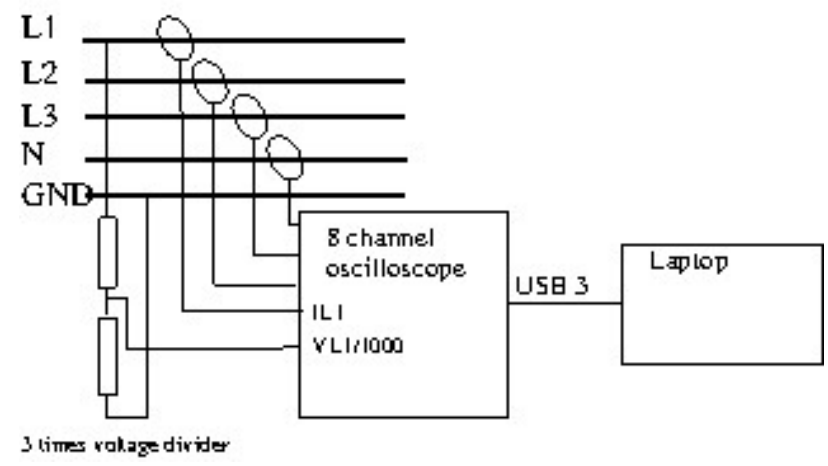

Figure 3: Measurement setup

Measurements have been performed on the local grid near the distribution transformer and after the power measurement equipment used for calculating the invoice. In the Netherlands companies are also measured on reactive power, normal households are only measured on real power. The power meter used in this company was a static meter which uses an unknown algorithm for calculating the consumed and delivered power and the consumed reactive power used from the grid. This measuring device is sealed, so the measuring sensors are also unknown.

The currents measured on the public power distribution cabinet are shown in Figure 4.

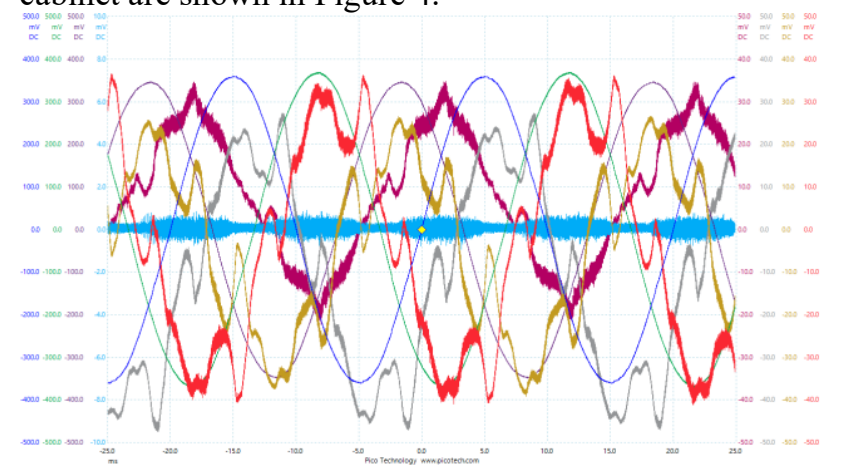

Figure 4 Current measurement on the infeed point

Figure 4 is rather cluttered but it shows the nice sinewave voltages and the rather distorted currents. The light blue line is the voltage on the neutral. There are double zero crossings in every phase current.

In Figure 5 an extract of Figure 4 is shown. 


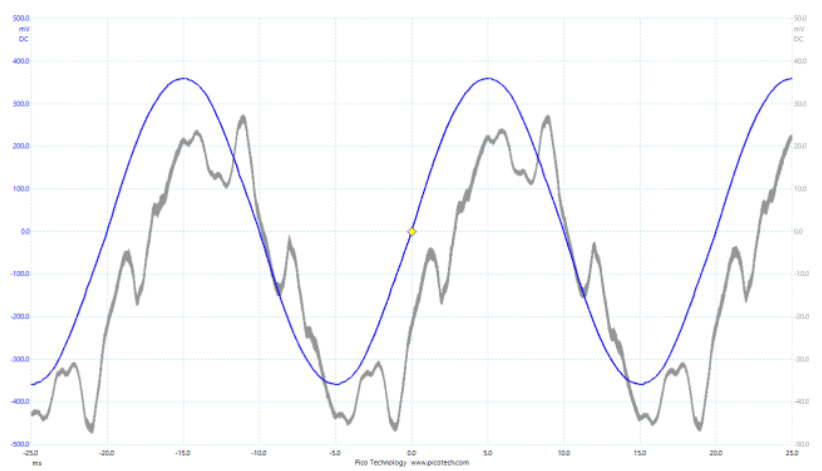

Figure 5: Line 1 voltage and current.

As the reader might notice a small DC offset in the current is shown. The cause of this offset is not "zeroing" the probe after switching it on.

The question arises on how the reactive power is measured. Is a small counter started at the zero crossing of the voltage and count how many degrees the current lags or leads? How does this work with a double zero crossing in the current?

Some calculations on the reactive power and spectrum of the measured voltages and currents have been performed. In Figure 6 the measured current is decomposed in his fundamental, reactive and harmonic components. This is done with the usage of public domain software under Linux, to be precise octave. Figure 6 shows that the fundamental current is approximately $300 \mathrm{~A}$ peak and the reactive current peaks at approximately $150 \mathrm{~A}$. The summation of all harmonic currents is the pink line.

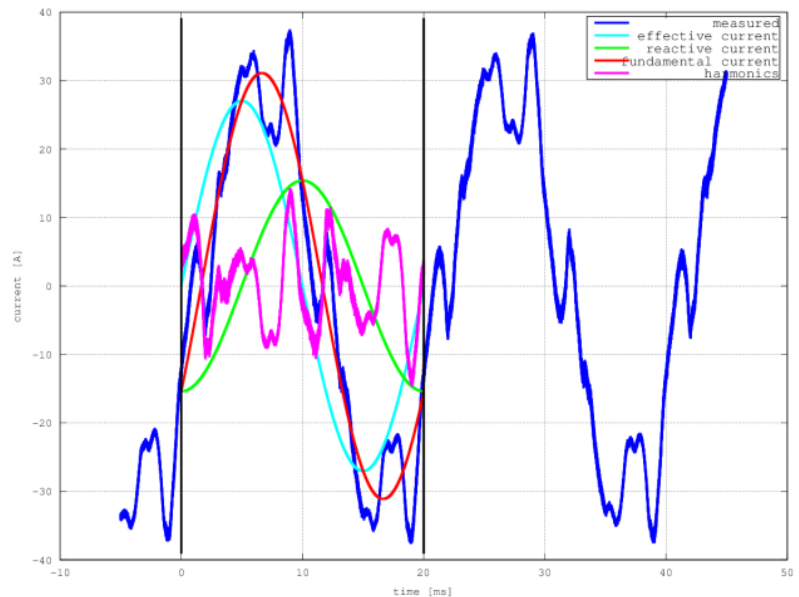

Figure 6: Octave calculations on the current of one phase

The two straight black lines are the zero crossing of the voltage wave, which we used as reference due to the inductive load of the company. The currents should be multiplied by two due to the fact that the main distribution board is connected by 2 wires per phase, as shown in Figure 7, but these currents have been measured and are exactly the same.

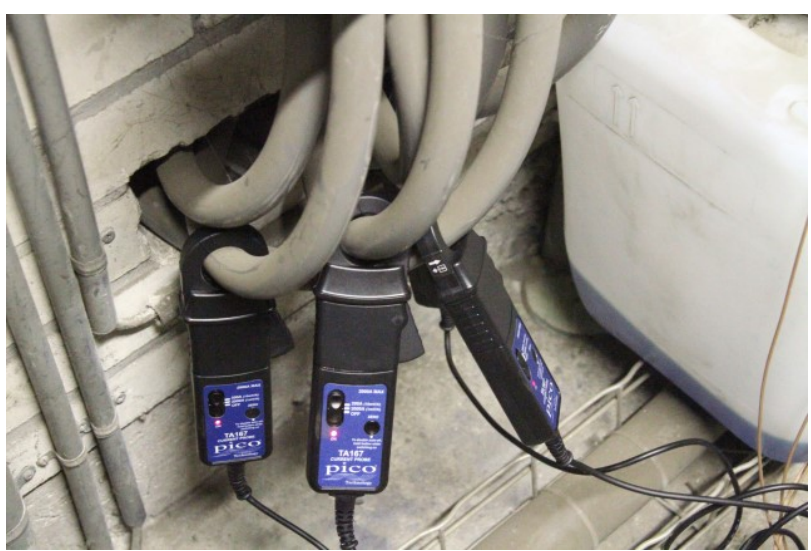

Figure 7: Main distribution board current measurement

\section{Reactive power consumption}

The reactive power consumed from the grid is limited by bylaw. The grid connection is in this case an industrial one with its own $10 \mathrm{kV} / 230 \mathrm{~V}$ transformer. The bylaw states that the amount of reactive power is dependent on the allowed $\cos \varphi$. In this case a $\cos \varphi$ of +0.85 is allowed which implies that $62 \%$ of the real power extracted from the grid is the basis for calculating the maximum reactive power drawn from the grid. The $62 \%$ is calculated from the allowed $\cos \varphi$ with the formula $\tan (\arccos (0.85))=$ 0.62 . Measurements are averaged over a period of 15 minutes and the results are summed over a period of 1 month, according [1].

The inverters used are from $\mathrm{ABB}$ and produce a nice clean sine wave voltage and current. These two are in phase so no reactive power is produced, although the inverters are capable to produce phase shifted current $\cos (\varphi)=\mp \quad$ so capacitive or inductive. On several places in the grid the inverters feed the power in from the photovoltaic generators. This real power is fed in so the real power drawn from the public grid is reduced. And in combination with the real power delivered by the PV installation this results in a reduction of real power from the grid. The reactive power, especially in periods of low local energy production, stays the same and this is drawn from the distribution grid.

In august 2014 the PV arrays were installed on the roofs and the generated energy over the last 4 months of 2014 was approximately $126 \mathrm{MWhr}$. The amount of green energy produced in 2015 is $411 \mathrm{MWhr}$, as shown in Figure 8 .

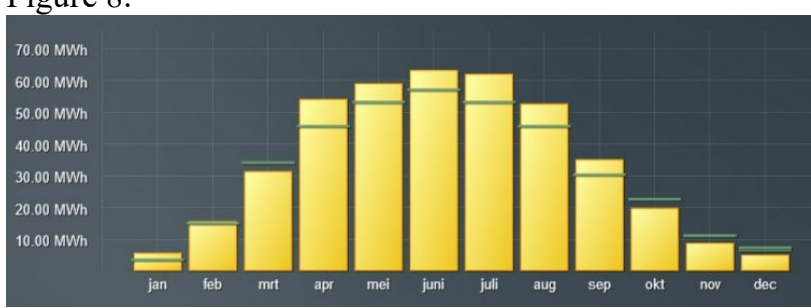

Figure 8: The energy generated in 2015 
Assuming the meters are functioning correctly and the reactive power is measured correctly, then we can do some simple math. The energy consumption over 2008-2013 was $626 \mathrm{MWhr} /$ year on average. The allowable reactive part drawn from the grid is then, taking $62 \%$ of 626 MWhr, 388 Mvar-hr per year, all before the installation of the PV arrays. Assume that the reactive part was less than $33 \%$, which is very low considering the high number of fans and machines used by this company. It is for $\cos \varphi=$ 0.95. This $33 \%$ is $207 \mathrm{Kvar}-\mathrm{hr}$.

The PV installation delivered $411 \mathrm{MWhr}$, so the net consumed energy from the grid is $626-411=215 \mathrm{MWhr}$, assuming that the total energy consumption by the company was the same in all years. The power utilities however compare the 207 reactive part to the $215 \mathrm{MWhr}$ real part, resulting in $96 \%$. This is much more than the allowable $62 \%$.

In another way, if $62 \%$ of the consumed 215 MWhr was allowed, then this is $21 \%$ of the total power consumption of $626 \mathrm{MWhr}$ which would mean that the $\cos \varphi=0.98$, averaged over 1 year. So in periods of high evergy production it is even impossible to stay below the threshold. It can also be concluded that the more clean PV energy in produced, the higher the fine can be from the utility.

This is a drawback on the financial advantage of using solar cells or alternative sources for electrical power. The owner of this company has to pay a fine for the amount of reactive power transported in the grid.

\section{Conclusion}

After installation of a photovoltaic renewable energy installation the owner has to pay a fine for producing too much reactive power. However, the inverters produce very clean and in-phase current-voltage energy. The consumed power from the public grid was reduced drastically, but the reactive power remained the same. The measurements are however averaged over 15 minutes and summed for a period of 1 month. Compared to the amount of consumed real power, the amount of reactive power increased dramatically. It is however a ratio, and not an absolute level. Because of the by-laws in The Netherlands, the company now has to pay a considerable fine for using the relative high amount of reactive energy, compared to the consumed real energy.

\section{Acknowledgement}

This work was partly funded by the European Union on the basis of Decision No 912/2009/EC, and identified in the European Metrology Research Program (EMRP) as Joint Research Project (JRP) IND60 EMC, Improved EMC test methods in industrial environments. Additional funding was received from Indonesian Ministry of Research, Technology, and Higher Education on the basis of Project No 8245-ID.

\section{References}

[1] Elektriciteitswet 1998 accessed on October 28th 2015, http://wetten.overheid.nl/BWBR0009755/geldigheidsdatum 2810-2015

[2] Frank Leferink, "Conducted interference, challenges and interference cases", IEEE Electromagnetic Compatibility Magazine, Volume 4, Quarter 1, 2015, pp. 78 - 85

[3] R.B. Timens, 'Electromagnetic interference of equipment in power supply networks', $\mathrm{PhD}$ thesis University of Twente, 2013, ISBN 978-90-365-0719-6

[4] Jörg Kirchhof, G. Klein, 'EMV - Grenzwertlücke Wechselrichter stört Zähler", 24. Symposium Photovoltaische Solarenergie, Bad Staffelstein, 2009

[5] CLC/TR 50579, Electricity metering equipment - Severity levels, immunity requirements and test methods for conducted disturbances in the frequency range $2-150 \mathrm{kHz}, 2012$

[6] IEC 61000-4-19: Electromagnetic Compatibility (EMC) - Part 419: Testing and measurement techniques - Test for immunity to conducted, differential mode disturbances and signalling in the frequency range from $2 \mathrm{kHz}$ to $150 \mathrm{kHz}$, at a.c. power port, 2014

[7] K. S. K. Weranga, Sisil Kumarawadu, D. P. Chandima, 'SSmart metering design and applications', Springer, ISBN 978-9814451-81-9, 2014

[8] Antonio Cataliotti, Valentina Cosentino, Alessandro Lipari, Salvatore Nuccio, "On the methodologies for the calibration of static electricity meters in the presence of harmonic distortion", 17th Symposium IMEKO TC 4, 3rd Symposium IMEKO TC 19 and 15th IWADC Workshop Instrumentation for the ICT Era, Sept. 8-10, 2010, Kosice, Slovakia, pages 167-172

[9] G. A. e Melo, A. Fazio Jr., L. P. Sampaio, M. A. G. de Brito, R. A. N. Oliveira, C. A. Canesin, 'Practical comparisons among electronic energy meters, a precision energy meter and IEEE1459 for reactive energy measurements, under unbalanced and nonsinusoidal conditions", 10th IEEE/IAS International Conference on Industry Applications (INDUSCON), 2012

[10] R. B. Timens, F. J. K. Buesink, V. Cuk, J. F. G. Cobben, W. L. Kling, F. B. J. Leferink, 'Large number of small non-linear power consumers causing power quality problems", 10th Int. Symposium on Electromagnetic Compatibility (EMC Europe 2011), York, UK, September 26-30, 2011, pp. 592-596

[11] IEEE Std 1459-2010, IEEE Standard Definitions for the Measurement of Electric Power Quantities Under Sinusoidal, Non-sinusoidal, Balanced, or Unbalanced Conditions, 2010 